Research Article

\title{
Hypothyroidism is Strongly Correlated with Mean Platelet Volume and Red Cell Distribution Width
}

\author{
Satilmis Bilgin*, Burcin Meryem Atak Tel, Gizem Kahveci, Tuba Taslamacioglu Duman, Ozge Kurtkulagi, \\ Semanur Yurum, Asli Erturk, Buse Balci, Gulali Aktas \\ Department of Internal Medicine, Abant Izzet Baysal University Hospital, Bolu, Turkey.
}

\begin{abstract}
Objective: Hypothyroidism is characterized with insufficient production and release of thyroid hormones, and cause a variety symptoms including cold intolerance, constipation, deceleration in movement, and hair loss. It is associated with increased inflammatory burden. Therefore, we aimed to observe red cell distribution width (RDW) and mean platelet volume (MPV) levels, novel predictors of inflammation, in patients with hypothyroidism and to compare to those in healthy subjects.
\end{abstract}

Materials and Methods: The subjects with hypothyroidism that show up in internal medicine outpatient clinics of Abant Izzet Baysal University Hospital between January 2020 and January 2021 were enrolled to the retrospective study. Healthy volunteers were enrolled as control subjects. MPV and RDW of the study groups were compared.

Results: The median RDW level of hypothyroid and control groups were $13.3(10-20.7) \%$ and $15.3(11.8-21.3) \%$, respectively (p<0.001). The median MPV level of hypothyroid and control groups were 10.2 (6.4-12.4) fL and 8.1 (5.4-11.5) fL, respectively (p<0.001). MPV levels greater than $9.47 \mathrm{fL}$ have $80 \%$ sensitivity and $72 \%$ specificity in predicting hypothyroidism (AUC: 0.66 [95\% CI: 0.58-0.74]; p<0.001). RDW levels greater than $13.4 \%$ have $80 \%$ sensitivity and 50\% specificity in predicting hypothyroidism (AUC: 0.67 [0.82 [95\% CI: $0.59-0.75$ ]; $\mathrm{p}<0.001)$.

Conclusion: We suggest that elevated MPV and reduced RDW levels should alert physicians for hypothyroidism in otherwise healthy subjects.

Keywords: Hypothyroidism, Red cell distribution width, Mean platelet volume, Inflammation, Thyroid hormones, Predictor, Retrospective study.

\section{INTRODUCTION}

Hypothyroidism is characterized with insufficient production and release of thyroid hormones, particularly thyroxin (FT4). Cold intolerance, constipation, deceleration in movement, and hair loss are among the large scale of the symptoms of the disease.

Thyroid hormones may have an ameliorating role in oxidative stress and inflammation [1]. Therefore, hypothyroidism could be associated with increased inflammatory burden. Indeed, raised c-reactive protein levels in serum was shown to be accompanied to subclinical hypothyroidism [2]. This finding was subsequently suggested by various reports in literature [3, 4].

Recent studies were focused on the role of hemogram derived inflammatory indices in inflammatory diseases characterized with either low or prominent level of inflammation. Red cell distribution width (RDW) and mean platelet volume (MPV) are among these indices. MPV has been suggested to be associated with infectious [5, 6], metabolic [7-9] and inflammatory conditions [10-13]. MPV is also increased in thyroid conditions $[14,15]$.

*Address correspondence to this author at the Department of Internal Medicine, Abant Izzet Baysal University Hospital, Bolu, Turkey. Email: drsatilmisbilgin@gmail.com
Association between RDW and inflammatory [11, 16-18] and metabolic conditions $[19,20]$ has been well established. Elevated RDW levels were reported in thyroid conditions, too $[21,22]$. Therefore we hypothesized that MPV and RDW could be associated with hypothyroidism.

For this purpose, we aimed to observe MPV and RDW levels of the subjects with hypothyroidism and to compare to those in healthy subjects.

\section{MATERIALS AND METHODS}

After getting approval from the ethics committee (approval number: 2021/134). Those who applied to Bolu Abant Izzet Baysal University, department of internal medicine clinic before, had a diagnosis of hypothyroidism and used levothyroxine sodium (LT4) treatment for this purpose between January 2020 and January 2021 were enrolled to the retrospective study. The control group was selected from healthy individuals who visited outpatient clinics of our institution for a routine checkup and considered healthy according to the physical examination and laboratory test results. Patients with hypothyroidism under 18 age, active infection, pregnancy, chronic renal failure, inflammatory diseases (such as; rheumatoid arthritis, sjogren's syndrome etc.), cancer, lymphoma, liver cirrhosis, anemia, and patients with myeloproliferative diseases were excluded from the study. 
Age, gender, other chronic diseases, glucose, serum urea, creatinine, aspartate aminotransferase (AST), alanine aminotransferase (ALT), erythrocyte sedimentation rate (ESR), C-reactive protein (CRP), leukocyte (WBC), neutrophil (NEU), lymphocyte (LYM), eosinophil (EO), monocyte (MONO), hemoglobin (HGB), hematocrit (HCT), mean corpuscular volume $(\mathrm{MCV})$, red cell distribution width (RDW), platelet (PLT), mean platelet volume (MPV), platelet distribution width (PDW) values were recorded retrospectively. Patients with hypothyroidism were named as group A, and healthy controls were named as group B. Variables of the study groups were compared.

SPSS software (SPSS for Windows 15.0, IBM Co, Chicago, IL, USA) was used in conduction of the statistical analyses. Normality of the study variables was analyzed by Shapiro Wilk test. Independent samples t-test was used in comparison of the normally distributed variables and these variables were expressed as mean \pm standard deviation. Mann Whitney U test was used comparison of the non-normally distributed variables and these variables were expressed as median (min-max). Categorical variables were expressed as numbers and percentage and compared with $\mathrm{X}^{2}$ test. ROC curve analysis was also performed to determine the predictive ability of MPV and RDW in detecting hypothyroidism. It was considered statistically significant when the $\mathrm{p}$ value was lower than or equal to $5 \%$.

\section{RESULTS}

We analyzed data of 188 subjects in the study; 94 were in group A (hypothyroidism) and 94 in group B (healthy control). Median age of group A and group B were 50 (19-87) years and 55(26-79) years, respectively $(\mathrm{p}=0.53)$. The group A consisted of $12(12.8 \%)$ men and $82(87.2 \%)$ women while group B consisted of 56 (59.6\%) men and 38 (40.4\%) women $(\mathrm{p}<0.001)$.

The mean PLT level of groups were $298 \pm 72.4$ and $271 \pm 79$, respectively $(p=0.01)$. The mean HCT level of groups were $39.9 \pm 4$ and $42 \pm 4.6$, respectively $(\mathrm{p}=0.001)$. The median free T4 level of groups were $1.01(0.62-1.45) \mathrm{pg} / \mathrm{mL}$ and 0.99 $(0.58-1.51)$, respectively $(\mathrm{p}=0.39)$. The median TSH level of groups were $1.64(0.01-100 \mathrm{mg} / \mathrm{dL})$ and 2,6 (0.87-4.1), respectively $(\mathrm{p}<0.001)$.

The median WBC level of groups were 7.26 $(3.62-14.3) \mathrm{k} / \mathrm{mm}^{3}$ and $7.63(4.53-14.9) \mathrm{k} / \mathrm{mm}^{3}$, respectively $(\mathrm{p}=0.03)$. The median NEU level of groups were 4.1 $(1.76-9.73) \mathrm{k} / \mathrm{mm}^{3}$ and $4.43(1.98-10.30) \mathrm{k} / \mathrm{mm}^{3}$, respectively $(\mathrm{p}=0.1)$. The median LYM level of groups were 2.2 $(0.86-4.08) \mathrm{k} / \mathrm{mm}^{3}$ and $2.27(1-4.62) \mathrm{k} / \mathrm{mm}^{3}$, respectively $(\mathrm{p}=0.04)$.

The median HGB level of groups were 13.1 (8.8-16.1)g/dL and $14(9.8-18.2) \mathrm{g} / \mathrm{dL}$, respectively $(\mathrm{p}<0.001)$. The median
MCV level of groups 86.3 (66-97.5) fL and 86.3 (67.9-102) $\mathrm{fL}$, respectively $(\mathrm{p}=0.67)$.

The median RDW level of groups were $13.3(10-20.7) \%$ and $15.3(11.8-21.3) \%$, respectively $(\mathrm{p}<0.001)$. The median MPV level of groups were 10.2 (6.4-12.4) fL and 8.1 (5.4-11.5) fL, respectively $(p<0.001)$. Fig. (1) shows the MPV and RDW values of the study and control groups.

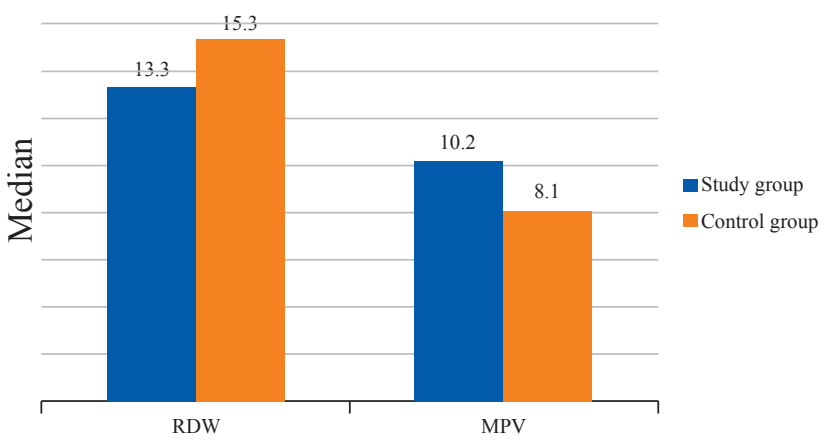

Fig. (1). Median Red cell Distribution Width (\%) and Median Mean Platelet Volume (fL) Values of the Study and Control Groups.

Fig. (2) shows the ROC curves of MPV and RDW. The ROC curve analysis revealed that MPV levels greater than $9.47 \mathrm{fL}$ have $80 \%$ sensitivity and $72 \%$ specificity in predicting hypothyroidism (AUC:0.66 [95\% CI:0.58-0.74]; p<0.001). This value is obtained from the ROC curve at a point with the highest sensitivity and specificity. RDW levels greater than $13.4 \%$ have $80 \%$ sensitivity and $50 \%$ specificity in predicting hypothyroidism (AUC: 0.67 [0.82 [95\% CI: 0.59-0.74]; $\mathrm{p}<0.001)$.

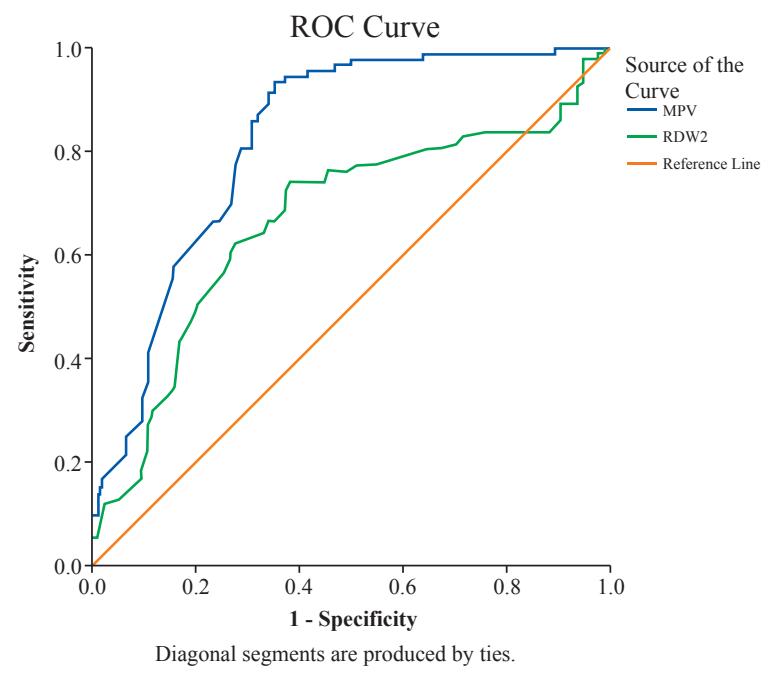

Fig. (2). ROC curve of MPV and RDW in Predicting Hypothyroidism (Cut off point red spotted). 


\section{DISCUSSION}

In present study, we showed that hypothyroid subjects have greater MPV levels compared to healthy control group. MPV has significant positive correlation with the presence of hypothyroidism. Moreover, MPV has considerable sensitivity and specificity in detecting hypothyroidism. Another important outcome of the study was reduced RDW levels in hypothyroid subjects compared to healthy control group. In addition, RDW was inversely and significantly correlated with the presence of hypothyroidism in present retrospective cohort study.

Mean platelet volume is associated with infectious, metabolic and inflammatory conditions. There are also various studies in the literature regarding the relationship between MPV and thyroid diseases. Kutluturk et al. reported that MPV level were greater in subclinic hyperthyroid subjects than euthyroid subjects [23]. Kim et al. showed that MPV level were greater in subclinic hypothyroid patients [24]. Another study showed that patients with subclinical hypothyroidism had significantly higher MPV levels than those with euthyroid [25]. Sit et al. reported that higher MPV levels in malignant thyroid nodules compared to benign nodules [15]. In our study, we found that MPV levels were significantly higher in patients with hypothyroidism compared to the healthy control group. Moreover, we showed that MPV was inversely and significantly correlated with hypothyroidism.

We shall speculate about the possible mechanisms of MPV elevation in hypothyroidism. Hypothyroidism is considered as a condition characterized with clinic/subclinic inflammation [26]. Inflammatory markers increase in blood during inflammatory process and could interfere with platelet production in bone marrow, resulting in production of larger platelet. This situation become overt with increased MPV in laboratory studies.

RDW levels, another important point in our study, were found to be significantly lower in the hypothyroid group. Similarly, when the literature was examined, lower RDW values were found in patients with hypothyroidism [26]. It has been reported increased RDW values in patients with Hashimoto's thyroiditis [22]. It has been also reported that higher RDW values in malignant thyroid nodules compared to benign nodules [21]. Min Yu et al. reported that RDW levels were correlated with subclinical hypothyroidism subjects than euthyroid subjects [27]. In the literature, different studies have been stated about whether RDW is high or low in thyroid disorders.

\section{LIMITATIONS}

Our study has two limitations: first limitation could be relatively small study population and second limitation could be retrospective design. These limitations make our results difficult to interpret in clinical practice. However, present study is important by showing increased MPV and decreased RDW in subjects with hypothyroidism, which may add a lot to the current literature knowledge.

\section{CONCLUSION}

We suggest that elevated MPV and reduced RDW levels should alert physicians for hypothyroidism in otherwise healthy subjects. Yet, prospective studies with greater study population are required to confirm our results.

\section{AUTHORS' CONTRIBUTION}

- Satilmis Bilgin, Semanur Yurum and Gulali Aktas designed the study.

- Satilmis Bilgin, Burcin Meryem Atak Tel, Ozge Kurtkulagi and Gizem Kahveci collected the data.

- Tuba Taslamacioglu Duman, Asli Erturk and Buse Balci performed literature analysis.

- Satilmis Bilgin and Gulali Aktas performed statistical analyses.

- Satilmis Bilgin, Burcin Meryem Atak Tel, Tuba Taslamacioglu Duman and Buse Balci wrote the first draft.

- Ozge Kurtkulagi, Gizem Kahveci and Gulali Aktas performed critical revision of the manuscript.

\section{CONFLICT OF INTEREST}

Declared none.

\section{ACKNOWLEDGEMENTS}

Declared none.

\section{REFERENCES}

[1] Mancini A, Di Segni C, Raimondo S, et al. Thyroid hormones, oxidative stress, and inflammation. Mediat Inflamm 2016; 2016: 6757154. DOI: $10.1155 / 2016 / 6757154$

[2] Kvetny J, Heldgaard PE, Bladbjerg EM, Gram J. Subclinical hypothyroidism is associated with a low-grade inflammation, increased triglyceride levels and predicts cardiovascular disease in males below 50 years. Clin Endocrinol 2004; 61: 232-8. DOI: $10.1111 / j .1365-2265.2004 .02088 . x$

[3] Hueston WJ, King DE, Geesey ME. Serum biomarkers for cardiovascular inflammation in subclinical hypothyroidism. Clin Endocrinol 2005; 63: 582-7. DOI: $10.1111 /$ j.1365-2265.2005.02388.x

[4] Tuzcu A, Bahceci M, Gokalp D, Tuzun Y, Gunes K. Subclinical hypothyroidism may be associated with elevated high-sensitive c-reactive protein (low grade inflammation) and fasting hyperinsulinemia. Endocr J 2005; 52: 89-94. DOI: 10.1507/endocrj.52.89

[5] Sit M, Aktaş G, Yilmaz EE, Hakyemez IN, Alçelik A, Küçük- 
bayrak A. Platelet parameters in hepatic hydatid cysts. Int J Inflamm 2013; 2013: 593273. DOI: 10.1155/2013/593273

[6] Aktas G, Cakiroglu B, Sit M, et al. Mean platelet volume: A simple indicator of chronic prostatitis. Acta Medica Mediterranea 2013; 29: 551-4.

[7] Cakir L, Aktas G, Enginyurt O, Cakir SA. Mean platelet volume increases in type 2 diabetes mellitus independent of HbA1c level. Acta Medica Mediterranea 2014; 30: 425-8.

[8] Aktas G, Kocak MZ, Duman TT, et al. Mean Platelet Volume (MPV) as an inflammatory marker in type 2 diabetes mellitus and obesity. Bali Med J 2018; 7: 650-3. DOI: 10.15562/bmj.v7i3.806

[9] Sincer I, Gunes Y, Mansiroglu AK, Cosgun M, Aktas G. Association of mean platelet volume and red blood cell distribution width with coronary collateral development in stable coronary artery disease. Adv Intervent Cardiol 2018; 14: 263-9. DOI: 10.5114/aic.2018.78329

[10] Aktas G, Sit M, Tekce H, et al. Mean platelet volume in nasal polyps. West Indian Med J 2013; 62: 515-8. DOI: 10.7727/wimj.2013.011

[11] Cakir L, Aktas G, Mercimek OB, Enginyurt O, Kaya Y, Mercimek K. Are red cell distribution width and mean platelet volume associated with rheumatoid arthritis? Biomed Res 2016; 27: 292-4.

[12] Karagoz I, Aktas G, Yoldas H, et al. Association between hemogram parameters and survival of critically ill patients. J Intensive Care Med 2019; 34: 511-3. DOI: $10.1177 / 0885066617703348$

[13] Aktas G, Duman T, Atak B, et al. Irritable bowel syndrome is associated with novel inflammatory markers derived from hemogram parameters. Fam Med Primary Care Rev 2020; 22: 107-10. DOI: $10.5114 /$ fmpcr.2020.95311

[14] Sit M, KArgi E, Aktas G, Dikbas O, Alcelik A, Savli H. Mean platelet volume should be a useful indicator in diagnosis of Hashimoto's thyroiditis. Acta Medica Mediterranea 2014; 30: 1263-6.

[15] Sit M, Aktas G, Ozer B, et al. Mean platelet volume: An overlooked herald of malignant thyroid nodules. Acta Clin Croatica 2019; 58: 417-20. DOI: 10.20471/acc.2019.58.03.03

[16] Aktas G, Alcelik A, Tekce BK, Tekelioglu V, Sit M, Savli H. Red cell distribution width and mean platelet volume in patients with irritable bowel syndrome. Przeglad Gastroenterologiczny 2014; 9: 160-3. DOI: 10.5114/pg.2014.43578
[17] Dagistan Y, Dagistan E, Gezici AR, et al. Could red cell distribution width and mean platelet volume be a predictor for lumbar disc hernias? Ideggyogyaszati szemle 2016; 69: 411-4.

[18] Aktas G, Alcelik A, Tekce BK, et al. Mean platelet volume and red cell distribution width in hepatosteatosis. Nat J Med Res 2013; 3: 264-6.

[19] Bilgin S, Aktas G, Zahid Kocak M, et al. Association between novel inflammatory markers derived from hemogram indices and metabolic parameters in type 2 diabetic men. Aging Male 2020; 23: 923-7. DOI: 10.1080/13685538.2019.1632283

[20] Tekce H, Kin Tekce B, Aktas G, Tanrisev M, Sit M. The evaluation of red cell distribution width in chronic hemodialysis patients. Int $\mathrm{J}$ Nephrol 2014; 2014: 754370. DOI: $10.1155 / 2014 / 754370$

[21] Aktas G, Sit M, Karagoz I, et al. Could red cell distribution width be a marker of thyroid cancer? J Coll Physicians Surg Pak 2017; 27: 556-8.

[22] Aktas G, Sit M, Dikbas O, et al. Could red cell distribution width be a marker in Hashimoto's thyroiditis? Exp Clin Endocrinol Diabetes 2014; 122: 572-4.

[23] Kutluturk F, Gul SS, Sahin S, Tasliyurt T. Comparison of mean platelet volume, platelet count, neutrophil/ lymphocyte ratio and platelet/lymphocyte ratio in the euthyroid, overt hypothyroid and subclinical hyperthyroid phases of papillary thyroid carcinoma. Endocr Metabol Immune Disord Drug Targets 2019; 19: 859-65. DOI: $10.2174 / 1871530319666190206125545$

[24] Kim JH, Park JH, Kim SY, Bae HY. The mean platelet volume is positively correlated with serum thyrotropin concentrations in a population of healthy subjects and subjects with unsuspected subclinical hypothyroidism. Thyroid 2013; 23: 31-7. DOI: $10.1089 /$ thy. 2012.0033

[25] Yilmaz H, Ertuğrul O, Ertuğrul B, Ertuğrul D. Mean platelet volume in patients with subclinical hypothyroidism. Platelets 2011; 22: 143-7. DOI: 10.3109/09537104.2010.508130

[26] Anagnostis P, Efstathiadou ZA, Slavakis A, et al. The effect of L-thyroxine substitution on lipid profile, glucose homeostasis, inflammation and coagulation in patients with subclinical hypothyroidism. Int J Clin Pract 2014; 68: 857-63. DOI: 10.1111/ijcp.12394

[27] Yu HM, Park KS, Lee JM. The value of red blood cell distribution width in subclinical hypothyroidism. Arq Brasil Endocrinol Metabol 2014; 58: 30-6. DOI: $10.1590 / 0004-2730000002836$ 